\title{
Hacia la marginalidad de las mujeres en el Reino de Granada (1487-1540)
}

\author{
M. a TERESA LOPEZ BELTRAN \\ Universidad de Málaga
}

\section{INTRODUCCION}

En la sociedad estamental y patriarcal de la época eran muchas las personas que recibían un trato discriminatorio por motivos muy' diversos: además de la frontera jurídica entre la libertad y la esclavitud, muchas personas tuvieron una consideración diferente e inferior a los demás por razones tales como el lugar de origen o procedencia, la religión o la raza, ciertas enfermedades o defectos físicos, la miseria, ciertas normaś de conducta, a todo lo cual hay que añadir el sexo, ya que las mujeres de cualquier condición estaban por debajo de los hombres de su propia clase o grupo.

Pero el trato discriminatorio no implicaba, en modo alguno, una existencia en los márgenes del sistema, a no ser que la pobreza se conjugase con una o varias de las razones apuntadas, porque la divisoria entre la pobreza y la marginalidad era muy frágil y los pobres, mezclándose con delincuentes y criminales, acababan, en muchos casos, engrosando las filas de la marginalidad.

Los grados de la pobreza eran diversos, del mismo modo que lo eran los factores que la generaban (1). No es mi intención centrarme en la casuística de la pobreza, pero sí quiero insistir en una forma de pobreza que cobra cada vez más pujanza en la sociedad urbana occidental desde el siglo XIV y que constituye el referente familiar más importante en la vida cotidiana de muchas mujeres que, en un momento más o menos temprano de su existencia, se ven abocadas a la marginalidad. Me refiero a la pobreza laboriosa, "la vivida por personas que ejercen un oficio regular, pero insuficiente para permitirles vivir decentemente, a ellos y a sus familias, si es que tienen una". Es una pobreza "discreta, hasta secreta, hecha de mala nutrición crónica, de dificultades de alojamiento y de vestido, sin esperanza ni alivio, privada en la mayoría del tiempo de la asistencia otorgada a las formas expectaculares de la indigencia de los mendigos, vagabundos y otros marginados" (2).

(1) M. MOLLAT: Pobres, bumildes y miserables en la Edad Media, México, 1988, en particular los capítulos IX, X y XI.Asimismo, Carmen LOPEZ ALONSO: La pobreza en la España medieval, Madrid, 1986, y "Mujer medieval y pobreza", La condición de la mujer en la Edad Media, Madrid, 1986, pp. 261-272. Igualmente, $\mathrm{M}^{\mathrm{a}}$ del Carmen CARLE: La sociedad hispanomedieval. Grupos periféricos: las mujeres y los pobres, Buenos Aires, 1988.

(2) M. MOLLAT: op. 'cit., pp. 149 y 222. 
Hombres y mujeres se hallaban inmersos en la pobreza laboriosa, pero las mujeres eran más vulnerables a la marginalidad porque su conducta estaba severamente controlada y cualquier circunstancia moral, fuese por la razón que fuese, las discriminaba frente al hombre y frente al sector de "mujeres honradas".

En efecto, si la pobreza dificultaba la plena integración social de hombres y mujeres, la mala reputación de una mujer -fuese cierta o no- significaba, en no pocos casos, la ruptura con la familia y con el entorno social, bien porque había sido expulsada, bien porque había decidido emigrar a otro lugar tras considerar que no tenía cabida o que se sentia a disgusto.

Pobreza y mala reputación eran, por tanto, ingredientes que potenciaban la marginalidad de las mujeres. Pero hay que tener en cuenta, además, que en la sociedad de la época, donde la mujer se definía por su relación al hombre, una mujer desvinculada de su entorno y de su familia incomodaba, suscitaba recelos y se convertía en el centro favorito de la difamación colectiva, puesto que su "independencia" comprometía el equilibrio social.

$\mathrm{El}$ recorrido seguido hasta desembocar en la marginación no fue el mismo para todas las mujeres. En unos casos, las mujeres conocieron la vida marginal desde el momento de su nacimiento, sin posibilidad de integrarse; en otros casos, pese a tener una infancia desgraciada, se procura integrarlas en el sistema por iniciativa institucional o de la propia familia; hubo mujeres que llegaron a casarse y formar una familia, pero la miseria o la rebeldía las empujaba coyuntural o definitivamente a la vida marginal; y hubo mujeres que no tuvieron otra opción que el concubinato o la prostitución. En fin, que las situaciones eran diversas y no resulta fácil trazar el recorrido hacia la marginalidad de manera rigurosa, pues no contamos con testimonios directos $y$, para el período que tratamos, no disponemos de testamentos de prostitutas, por lo que se hace indispensable la consulta de obras literarias referidas al tema, y en particular La lozana andaluza de Francisco Delicado (3).

\section{HACIA LA MARGINACION DESDE LA INFANCIA}

La finalidad de la mujer era el matrimonio o el convento, y en uno y otro caso la dote era requisito indispensable en todos los grupos sociales (4), lo que significaba que la hija de una familia pobre no tenía posibilidad de casarse, a menos que sus progenitores o parientes la colocasen desde su más tierna infancia con una familia que le garantizase una existencia menos pobre y le proporcionara, al alcanzar la edad de casarse y por el trabajo prestado, una pequeña remuneración en concepto de dote con la que acceder al matrimonio (5).

(3) Un jugoso aprovechamiento de la obra en A. MACKAY: "Averroístas y marginadas", Actas del III Coloquio de Historia Medieval Andaluza. La sociedad medieval andaluza: grupos no privilegiados (Jaén, 1984), pp. 247-261.

(4) Paloma DERASSE PARRA: Mujer y matrimonio. Málaga en el tránsito a la modernidad. Mála$\mathrm{ga}, 1988$.

(5) $M^{2}$ T. LOPEZ BELTRAN: "La accesibilidad de la mujer al mundo laboral: el servicio doméstico en Málaga a finales de la Edad Media", Estudios bistóricos y literarios sobre la mujer medieval, Málaga, 1990, pp. 121-142. Asimismo, Gloria LORA SERRANO: "El servicio doméstico en Córdoba a fines de la Edad Media", Actas del III Coloquio de Historia Medieval Andaluza..., pp. 237-246; M를 Carmen GARCIA HERRERO: "Mozas sirvientas en Zaragoza durante el siglo XV", El trabajo de las mujeres en la Edad Media bispana, Madrid, 1988, pp. 275-285. 
De este modo, con edades que oscilaban entre los dos años y medio y! los catorce, las hijas de familias menesterosas se veían desarraigadas del hogar y de los suyos durante años para trabajar como domésticas hasta llegar a la edad casadera (entre dieciocho y veinte años), sin posibilidad, en la mayoría de los casos, de acceder al aprendizaje de un oficio mínimamente cualificado.

Sin el respaldo de sus familias y a disposición de los amos para realizar trabajos dentro y fuera de la casa, estas niñas constituían un grupo de alto riesgo como víctimas de la violación, lo que justifica que en más de un contrato se incorporen cláusulas tendentes a preservar su integridad moral. Así, Ana Reyes, que tenía una hija sirviendo con el escribano público Alonso Hernández del Alcázar, incluyó en el contrato que su hija "sirva en todas las cosas honestas de hacer dentro de las puertas de la calle adentro, y si hubiere de salir fuera que sea como hija o sobrina del dicho Alonso..." (6). Asimismo, el padre de Juana, que entra a servir con una familia de la ciudad, estipula que su hija "sirva de dentro de las puertas de la casa(...) y la han de doctrinar y guardar como hija propia y que no haya de salir fuera" (7). Más explícito aún fue García de la Podadera, que coloca a su sobrina con el cerrajero Juan Díaz con la condición de que la moza no vaya"a la tabernería ni a la alhóndiga ni a la carnicería" (8), de igual manera que Juan de Segovia prohíbe que su hija fuera "a la carnicería ni pescadería ni a la plaza y ni a cosa de las vecinas junto a casa" (9).

En ocasiones, pocas, el amo evitaba situaciones que pusieran en entredicho la reputación de la sirvienta (¿o era, tal vez, su propia reputación?), como fue el caso de Juan Gallego, hombre de la mar, que había tomado a servicio a una niña de diez años llamada Ana para que trabajase en su casa por espacio de diez años, pero cuando la niña tenía quince años enviuda, por lo que "por razón de que su mujer es fallecida y está 'viudo y porque [la moza] esté recogida en compaña honesta quien la tenga...", la traspasa en servicio a la viuda Ana de Palma (10).

Sin embargo, las relaciones sexuales con un servicio doméstico de muchachas indefensas y sin posibilidad de abandonar la casa debió ser usual, pese a que sólo he encontrado un testimonio en el que la moza había quedado embarazada a los dos años de estar sirviendo (11).

Tras largos años de servicio, sin apenas haber accedido a un aprendizaje, ocultando o no su deshonra, en algunos casos en condición de madres solteras, las muchachas recibían su pequeña remuneración en concepto de dote, siempre que los amos no pusieran impedimentos o que sus familias no hubiesen tomado por adelantado una parte más o menos sustancial de la misma. $Y$ en estas condiciones se independizaban para integrarse en la sociedad e intentar, en la medida de sus posibilidades, encontrar un marido.

También el servicio doméstico fue un recurso de integración para niñas huérfanas en las primeras fases de su existencia. Con una población inactiva, pre-

(6) A.H.P.M., leg. 5, 27/VII/1501.

(7) A.H.P.M., leg. 15, 22/X/1504.

(8) A.H.P.M., leg. 83, 8/I/1528.

(9) A.H.P.M., leg. $65,24 / \mathrm{X} / 1529$.

(10) A.H.P.M., leg. 153, 4/III/1533.

(11) M $\mathrm{a}^{\mathrm{a}} \mathrm{T}$. LOPEZ BELTRAN: op. cit., p. 134. 
sumiblemente excesiva, de forasteros ociosos, vagabundos, pobres, huérfanos y "malvivientes" (12), la integración o reinserción de los niños y niñas pobres y huérfanos se convierte, desde fechas tempranas, en un tema de preocupación para el regimiento malagueño, que consigue en diciembre de 1498 disponer de un letrado y procurador de pobres "para atender a los pobres, huérfanos y presos de la cárcel que fueran pobres y hubieran hecho o hicieren la solemnidad de pobres con el sueldo" (13).

La persona que detentaba el cargo de "padre de huérfanos", distinto al de "padre de menores" (14), tenía la obligación de evitar que niños y niñas sin padre o huérfanos de ambos progenitores conviviesen miserablemente con delincuentes y maleantes, colocándolos con familias de la ciudad (15). Y si los niños eran colocados indistintamente de sirvientes o aprendices, las niñas, por el contrario, sólo accedian al servicio doméstico, encontrándose al cumplir los dieciocho o veinte años, con unas expectativas similares a las de la sirvienta que no era huérfana, pero, sin duda, agravadas por su condición de solitaria.

Así, pues, el recurso más generalizado para integrar o reintegrar, en las primeras etapas de la infancia, a las hijas de familias pobres y a las huérfanas desamparadas era el servicio doméstico, pero no fue el único. Algunas familias recurrieron a fórmulas jurídicas que implicaban, de hecho o de derecho, la renuncia definitiva a la hija y que formaban parte de la estructura oculta del parentesco, como ya ha sido puesto de manifiesto por Goody (16), entre las que se encuentra el prohijamiento.

El prohijamiento o adopción fue una fórmula que, aunque presente en la sociedad malagueña desde finales del siglo XV, no empieza a generalizarse sino a partir de los años treinta del siglo XVI. Si desde la pobreza no había otra alternativa que desarraigar a las hijas del hogar, era preferible hacerlo garantizándoles la manutención, el alojamiento y el derecho a heredar el patrimonio más o menos significativo de una familia que, además, podía darle afecto. Y ese debió ser el planteamiento que se hicieron el hortelano Gómez Fernández y su mujer Aldonza Fernández, que dan en prohijamiento al zapatero García Romero y a su mujer

(12) En efecto, en 24 de marzo de 1494, el Concejo prohíbe la estancia en la ciudad a cualquier forastero que no tenga señor con quien viva u oficio en que trabaje, permitiéndole que se aloje en el mesón o la taberna no más de tres dias: A.M.M., L.A.C., I. Al mismo tiempo, se establecen dispositivos de control social de los vecinos a través de los jurados de las respectivas parroquias o colaciones para restablecer la moralidad pública: $M^{\mathrm{a}} \mathrm{T}$. LOPEZ BELTRAN: "Las transgresiones a la ideología del honor y la prostitución en Málaga a finales de la Edad Media", Las Mujeres en Andalucia. Actas del $2^{\circ}$ Encuentro Interdisciplinar de Estudios de la Mujer en Andalucía, II, Málaga, 1993, pp. 145-161. Las medidas represivas, aunque se promulguen utilizando sólo el masculino, afectaban por igual a hombres y mujeres. Confróntese Carmen LOPEZ ALONSO: Mujer medieval y pobreza, pp. 267 y ss.

(13) A.G.S., R.G.S., Diciembre, 1498, fol. 2.

(14) El "padre de menores", cargo cuya primera noticia de que disponemos data de enero de 1502 , solia ser asumido por jurados, que se encargaban de tomar las cuentas de los huérfanos menores de edad: $M^{\mathrm{a}}$ T. LOPEZ BELTRAN: La accesibilidad de la mujer..., pp. 137-138.

(15) $M^{2}$ T. LOPEZ BELTRAN: op. cit., loc. cit.

(16) J. GOODY: La evolución de la familia y del matrimonio en Europa, Barcelona, 1986, pp. 206 y ss. 
una hija llamada Juana, de cuatro años, porque éstos le tienen"amor y voluntad" a la niña $y$, como no tienen hijos, que la adoctrinen y cuiden como hija propia y que la dejen como heredera de sus bienes (17). Asimismo, la viuda Beatríz Hernández, que tiene una hija de ocho años llamada Costanza y es mujer pobre, deseando que su hija "esté y sirva en parte donde la dotrinen e doten que se pueda casar honestamente", la da en prohijamiento a una familia de la ciudad que nó tiene hijos, para que "después de sus días la han de dejar como legítima heredera de todos sus bienes" (18).

La condición de prohijada no significaba que la niña no tuviera que trabajar durante su infancia, pero posiblemente más como aprendiza que como sirvienta, o que su honra se hallara a' salvo por disfrutar de la protección cercana de la familia, pues hay testimonios de hijas prostituidas o violadas por padres o parientes. En estas situaciones, la gravedad del delito era mayor, era un atentado contra el sistema, ya que había sido provocado por quienes tenían la obligación jurídica de preservar el honor de las mujeres de la familia. Además, en el caso de la violación, el agresor sufría la condena eclesiástica, porque se consideraba una relación incestuosa (19).

Sirva como ejemplo el caso del mercader genovés Adán Rojo y de su mujer, que tuvieron que marcharse de Málaga, perdiendo la casa que les había tocado en repartimiento, porque "fue denunciado que eran alcaguetes de su hija" (20). O el de Alonso Díaz Cordobés, a quien su mujer acusa de haber violado a su hija, con la que había tenido "cópula carnal y se había hechado con ella carnalmente y avía avido su virginidad", y que tuvo que compensarla económicamente con 20.000 maravedís (21), cantidad más que llamativa, si se la compara con otras compensaciones otorgadas a muchachas por agresores ajenos a la familia de la víctima (22).

De todos modos, las muchachas que contaban con la protección de la familia eran menos vulnerables a las agresiones contra su honor, que las que no contaban con el respaldo de los hombres de su familia, por lo que el matrimonio, para estas mujeres indefensas más que para las demás, significaba contar con un hombre que las protegiera. Pero, desde la pobreza, el hecho de formar parte de una familia con patrimonio (por minúsculo que éste fuera), de disponer de una dote decente y de haber aprendido un oficio, establecía ventajas entre unas mujeres y otras. Y mientras unas consiguen casarse, otras buscarán en el concubinato o en la prostitución una opción.

\section{EL MATRIMONIO: ENTRE LA POBREZA Y LA DESILUSION}

El matrimonio era más un contrato económico; que la consecuencia lógica del cariño y la atracción sexual. Y, en el contexto de la pobreza laboriosa, el

(17) A.H.P.M., leg. 1, tomo I, 4/II/1496.

(18) A.H:P.M., leg. 74, 8/V/1535.

(19) Ana ARRANZ GUZMAN: "Imágenes de la mujer en la legislación conciliar (ss. XI-XIV)", Las mujeres medievales y su ámbito juridico, Madrid; 1983, pp. 33-43.

(20) Fco. BEJARANO ROBLES: 'Los Repartimientos de Málaga, vol. II, Málaga, 1990, p. 63: 2 de marzo de 1493.

(21) A.H.P.M., leg. 104, 7/IV/1525

(22) M' 'T. LOPEZ BELTRAN: La prostitución en el reino de Granada en época de los Reyes Católicos: el caso de Málaga (1487-15l6), Málaga, 1985, pp. 100-102. 
matrimonio adquiere los perfiles de un frágil negocio que exige invertir toda la fuerza de trabajo disponible, de manera que el trabajo de las mujeres, dentro y fuera del hogar, era tan necesario e importante como el de los hombres (23).

Esta permanente fragilidad económica en la que vivían las mujeres casadas, podía romperse con facilidad cuando los maridos se ausentaban, corriendo el riesgo de verse inmersas en la miseria. La ausencia prolongada de los maridos no era novedosa en una sociedad que se había forjado en la conquista y repoblación (24), y en la que seguían vivas las expectativas de una vida mejor en unos horizontes geográficos cada vez más dilatados.

Ausente o no, la conducta moral de la mujer era competencia de su marido, en cuyas manos quedaba la decisión de matarla, de repudiarla, de desterrarla o de perdonarla. Y si en el hombre la reprobación social y la puesta en entredicho de su virilidad eran razones de peso para exigir un castigo, en la mujer la infidelidad conyugal respondía, en muchos casos, a la necesidad de sobrevivir o al deseo, muchas veces fallido, de iniciar una vida menos insatisfactoria con otro hombre y en otro lugar.

Efectivamente, para sortear la miseria, algunas mujeres recurrieron a soluciones que les permitieran seguir dentro del sistema y sentirse protegidas, como era el caso de la bigamia (25). El trapero Juan de Castro, por ejemplo, que llevaba casado desde el año 1487, pierde su vivienda en el año 1493 porque su mujer "pareció ser casada dos veces" (26). El caso de Magdalena Martín, casada con Pedro García de la Podadera, fue distinto. El marido se ausenta de Málaga para combatir en la guerra de Orihuela y en otras partes, dejándola con muy poco "refriserio" y sin recibir noticias suyas durante seis años. A ella le habían dicho que su marido había muerto y "por quedar pobre y necesitada", se casó por segunda vez legítimamente con Pedro Hernández, trabajador afincado en Málaga y natural de Ecija, "lo cual hizo por vivir bien y honestamente como buena mujer, y con èl ha hecho vida maridable en uno como marido y mujer legítimos". Pero, el marido regresa y reinician la vida conyugal, pues él no la acusa de adulterio (27).

En otras ocasiones, las mujeres cuyos maridos se hallaban ausentes iban a su encuentro, como hizo Juana de Dueñas, quien estando su marido al servicio de la Corona en la toma de Trípoli y Bugía, fue a buscarlo sin comunicárselo y el marido, que mientras tanto ya había regresado a Málaga, no la acusa de adulterio porque "no había hecho nada contra él" (28). Y no debieron ser infrecuentes los casos de mujeres casadas que se movían de un lugar a otro sin el permiso de sus maridos, pues el Concejo malagueño hubo de promulgar, en octubre de 1491, una ordenanza prohibiendo embarcar a las mujeres que no tuvieran licencia de sus maridos (29).

(23) Heath DILLARD: La mujer en la Reconquista, Madrid, 1993, cap. 6; Paulino IRADIEL: "Familia y función económica de la mujer en actividades no agrarias", La condición de la mujer en la Edad Media, Madrid, 1986, pp. 223-259; Ma T. LOPEZ BELTRAN: El trabajo extradoméstico en Málaga en el tránsito a la modemidad (en prensa).

(24) H. DILLARD: op. cit., en particular cap. 1.

(25) $\mathrm{M}^{\mathrm{a}}$ T. LOPEZ BELTRAN: La prostitución en el reino de Granada..., pp. 105-109.

(26) Fco. BEJARANO ROBLES: op. cit., 14/X/1493.

(27) A.H.P.M., leg. 63, 20/XI/1527.

(28) A.H.P.M., leg. 26, (?)/VIV/1511.

(29) $\mathrm{M}^{\mathrm{a}}$ T. LOPEZ BELTRAN: La prostitución en el reino de Granada..., pp. 107-109. 
De todos modos, los hombres disfrutaban de una libertad de movimientos de la que carecían por ley sus mujeres. Una mujer que se ausentara sin la autorización del marido era potencialmente una adúltera $y$, precisamente, la ausencia sin licencia era uno de los cargos que utilizaba el hombre cuando acusaba a su mujer de adúltera (30).

Si la bigamia y la ausencia sin permiso podían dar a la mujer un cierto margen de juego para justificar su conducta sexual ante el marido, en el adulterio no cabía justificación posible: la mujer era denunciada por el marido, se convertía en prófuga y su destino era diverso. Algunas jamás fueron recuperadas para los maridos; otras, localizadas por la justicia y devueltas a sus maridos, quedaban a merced de la "piedad marital", que el hombre aplicaba a la medida de sus intereses; y otras, siguieron manteniendo una actitud de rebeldia contra sus maridos. Así, Juan de Villanueva, vecino de Guadix, cuya mujer había sido castigada por adúltera con la vergüenza pública y el destierro, estaba dispuesto a perdonarla si ella se arrepentía públicamente, "pero ella lo puso de tal forma en evidencia, que él con un palo le hizo una herida en la cabeza que le provocó la muerte" (31). Igualmente, Marcos de Segura, vecino de Marbella, que había perdonado a su mujer de un primer adulterio porque tenían una hija, se ve obligado a matarla a cuchilladas porque, a los dos meses y medio de haber ella regresado, se volvió a escapar con "un Diego de Astorga, con el que tenía pensado huir a Levante en una nao" (32).

De las mujeres adúlteras, interesa centrarnos en aquellas que habían huído de sus maridos y no habían sido localizadas por la justicia, o fueron localizadas después de transcurrido un cierto tiempo. ¿Qué recursos tenían aquéllas mujeres?. Vivir de lo que fuera posible para subsistir y, en el mejor de los casos, encontrar un hombre con el que poder mantener una relación estable. Tal fue lo, ocurrido a Isabel Rodríguez, casada en Las Brozas de Alcántara con Julián Alonso, que abandona marido y lugar para marcharse a Cáceres y a otras partes, "haciendo lo que le apetecía", hasta que en Málaga conoce a Juan de Herrera, con el que mantiene una relación estable. Su marido la localiza al cabo de los siete años y la perdona, aunque se la lleva, "porque él tuvo en Málaga información de que vivía honestamente" y porque en la ciudad estaba "de asiento y haciendo vida maridable" con el susodicho Juan de Herrera (33).

Desde la pobreza, no resultaba fácil llegar a una separación de mutuo acuerdo (34), y las mujeres optaban por la ruptura unilateral y delictiva, viéndose abocadas a la prostitución o al amancebamiento para subsistir.

(30) R. CORDOBA DE LA LLAVE: "Violencia y adulterio en la Andalucía bajomedieval", Actas del III Coloquio de Historia Medieval Andahuza..., pp. 263-273; "Relaciones extraconyugales en la sociedad castellana bajomedieval", Anuario de Estudios Medievales, 16 (Barcelona, 1986), pp. 571619. J. TOLEDANO GALERA: "Tensiones de la vida cotidiana en Martos a finales del siglo XV: violación y adulterio", Boletin del Institutó de Estudios Giennenses, t. XXXIV (141), pp. 105-115.

(31) A.G.S., R.G.S., Agosto, 1497, fol. 104.

(32) A.G.S., R.G.S., Octubre, 1495, fol. 274.

(33) A.H.P.M., leg. 7, 20/V/1502.

(34) Tan sólo dispongo de un testimonio en el que se llega a la separación por mutuo acuerdo, tras haber una denuncia de huída. Se trata del matrimonio de Granada formado por Juan García y Francisca Fernández, que tras vivir ciertos años casados, ella huye a Málaga y el marido acaba localizándola. Ambos llegan al acuerdo de "apartarse (...) de manera que cada uno gozare de su libertad sin que fueren apremiados ni molestados por ninguna vía...": A.H.P.M., leg. 110, 27/X/1533. 
Ambas condiciones estaban penalizadas, pero, mientras la prostitución podía significar una existencia sin estima personal, el amancebamiento permitía a una mujer integrarse en el entorno social y vivir sin la reprobación colectiva, siempre que se supiera poco de su pasado y hasta que fuese localizada por la justicia. El control social surtía efecto entre los vecinos, pero no tanto con forasteros venidos de otro lugar. De ahí que el amancebamiento de una vecina casada tuviera muy poco futuro y se castigara con el destierro. Tal fue lo ocurrido a Guiomar Fernández, vecina de Málaga y casada con Pedro Navarro, que mientras su marido se hallaba cautivo en allende, se amancebó con el boticario valenciano Esteban Bonora, lo que motiva que pierda la vivienda y se la destierre de la ciudad (35).

El matrimonio era un vínculo indisoluble hasta la muerte. Pero hubo mujeres que no esperaron a quedar viudas, negándose a una convivencia que no las gratificaba. Es cierto que los testimonios que disponemos son pocos (lo que puede ser indicativo de que no era lo usual) y que se refieren a mujeres que cuentan con el respaldo de sus familiares, pero no por ello dejan de ser significativos. El primero de ellos se refiere al matrimonio formado por Ruy Pérez Delgado y Francisca Gutiérrez, que vivieron casados durante veinticinco años hasta que ella, "por razón de la mala vida que me davades y de otras cosas", pidió al juez eclesiástico que los separara. Tras vivir separados durante diez años, deciden "unirse como lo estaban antes, para continuar el dicho matrimonio", decisión que toman ante notario, en presencia de una hija casada y del yerno (36). El otro ejemplo es el de Alonso García, vecino de Alora y casado con María de la Paz, hija del labrador malagueño Juan Alvarez. Por razones no manifiestas, María se niega a vivir con su marido y se refugia en la casa paterna, originándose un largo pleito entre yerno y suegro, que no finaliza hasta que aquél acaba aceptando que su mujer viva con el padre (37).

Estos testimonios ponen de manifiesto que la ruptura conyugal por iniciativa de la mujer no siempre llevaba aparejada la pérdida de la estima de los vecinos. Pero no todas las mujeres contaban con familiares en los que apoyarse.

Como ya se ha visto, desde la pobreza, las distintas estrategias utilizadas por la mujer para afrontar el desencanto de la vida conyugal y las largas ausencias de un marido que, en ocasiones, jamás regresaba, tuvieron resultados diversos. Mientras unas mujeres continuaron bajo la tutela de sus maridos, con un indudable menoscabo de su reputación, otras no tuvieron posibilidad, o no quisieron, de seguir viviendo en una comunidad en la que se ponía en entredicho su estima o que la rechazaba. En tales condiciones, la huída era la única alternativa para muchas casadas que, como prófugas o como desterradas, querían seguir viviendo en otro lugar donde, en calidad de forasteras o residentes, se supiera lo menos posible de su pasado.

En consecuencia, desde el matrimonio y por las razones apuntadas, muchas mujeres iniciaron una andadura hacia la marginación: la necesidad de ocultar su condición de casadas y su condición, casi permanente, de forasteras las aproxima a aquellas mujeres solteras que sólo han encontrado en el concubinato o en la prostitución una opción. Pero también las aproxima a las viudas sin recursos.

(35) Fco. BEJARANO ROBLES: op. cit., pp. 28 y 224: 26/II/1493.

(36) A.H.P.M., leg. 148, 15/I/1532.

(37) A.H.P.M., leg. 153, 7/XI/1533. 


\section{LAS MUJERES SOLITARIAS}

Si en el contexto de la pobreza laboriosa, resultaba difícil evitar la miseria y el hambre, la situación podía precipitarse cuando el marido faltaba, dejando a la familia en una situación precaria. Y la mujer viuda, que pasa a ocupar el lugar del marido, tiene el deber de sacar adelante los hijos y defender el escaso patrimonio de la familia, que muchas veces se reduce a la vivienda que han recibido como repobladores o heredada de sus progenitores.

Para unas viudas; la mejor opción era volverse a casar para asegurarse los ingresos de la familia y contar con la protección de un hombre: Para otras, por el contrario, el matrimonio se muestra como una experiencia irrepetible o muy alejada de su alcance; y buscan otras vías para solucionar sus problemas. Así, por ejemplo, Mari Fernández, iviuda del borceguinero Gonzalo Fernández y del que tenía tres hijas, se amancebó con Gonzalo de Horozco, "y ella confiesa aver parido del dos vezes después de la muerte de su marido, por lo quel dicho señor corregidor viendo su desonestidad e de como con poca verguença dixo antel que más quería ser manceba de un bueno que muger de un ruyn, le mandó que salga de la dicha casa oy en todo el día para proveer a otro vezino y a tres fijas que le quedaron del primero marido que se dizen Ysabel e Ynés e Antona..." (38).

Esta viuda perdió su casa cuando apenas le faltaba un año para cumplir su vecindad $\mathrm{y}$ acceder como plena propietaria de la misma, pero no pudo ser desterrada, puesto que no había marido al que ofender en su honor. Es más, siguió viviendo amancebada (39). Por otra parte, no fue el único caso, ya que las condenas por concubinato afectaban por igual a hombres y mujeres (40).

Hubo otras viudas que también perdieron la casa, no ya por estar amancebadas, sino por llevar una "vida no honesta", expresión ambigua que da a entender que se trataba de mujeres que se dedicaban a la prostitución con discreción. Así, por ejemplo, perdió la casa la viuda de Antón López de Enziso porque "no quedaron herederos e su muger ha byvydo menos onestamente" (41). Y lo mismo ocurrió con la viuda de Nuño López de Enziso, "porque ella ha bivido menos onestamente" (42). Por su parte, la viuda de Juan Sánchez Pelado retiene su casa "si viviere honestamente" (43), mientras que la viuda de Sebastián de la Vega no la pierde porque "ase de ver si se prueba lo que se denunció, porque averiguado se ha de proveer a otro" (44).

¿Qué había que demostrar?. Con toda probabilidad, que esa mujer había estado con un determinado número de hombres, cuya cantidad variaba de una

(38) Fco. BEJARANO ROBLES: op. cit., p. 38: 28/II/1493.

(139) A.C.M., leg. 63, pieza 15: "relación de la cuenta que se recibió de Juan Garrote, escribano de las'penas de la Cámara".

(40) Así, por ejemplo, pierde su casa por estar amancebado Juan López de Villarreal y Juan García 'de León, hermano este último del alarife Antón Rodríguez, 'porque no ba residido en la ciudad salvo poco tiempo y aquello desonestamente amancebado e agora se fue con sus mancebas segund se ovo ynformación..." Fco. BEJARANO ROBLES: op. cit., pp. 41 y $159 .$.

(41) Ibíd, p. 108: 21/III/1493.

(42) Ibid, p. 203: 30/XII/1493.

(43) Ibid, p. 92: 18/III/1493.

(44) Ibid, p. 108: 21/III/1493. 
comunidad a otra (45), de manera que la mujer quedaba a merced de la discreción de sus clientes, fuesen vecinos o forasteros.

Viudas también fueron las beatas, que, en ocasiones, son mujeres de vida intachable y que cumplían una función social importante, ayudando a cuantos vecinos las necesitaran (46). En otras ocasiones, las beatas gozaban de muy mala reputación, utilizándose el término como sinónimo de alcahueta o "puta devota" (47).

Si las viudas disfrutaban de una libertad de movimientos de la que carecian las casadas, las beatas se podían mover de un lugar para otro sin levantar sospechas, visitando a unos y otros. Buena beata fue Leonor Sánchez Zapata, que precisamente por su condición había recibido en repartimiento una casa (48). En el lado opuesto se encontraba la viuda Isabel Rodríguez, que también había recibido una casa porque ella había dicho que era "beata y vivía honesta y santamente" y porque el repartidor consideró que en las ciudades ha de haber "de las semejantes personas". Pero a los pocos años acaba perdiendo la casa, no tanto porque en ella había hecho dos tiendas y las alquilaba sin la correspondiente licencia municipal, sin vivir en la casa, sino fundamentalmente porque "también hay indicios que no vive honesta y castamente y ha sido certificado de muchas personas que no vive según el hábito" (49). Mala reputación tenía también Marina Sánchez, "de oficio beata", que tenía en su poder a Antonia, huérfana de seis años, hija natural del genovés Antonio Baso y de Juliana Trapanesa, difuntos, por la cual se interesa Francisco del Valle, que se desplaza de Sevilla a Málaga para saber de la niña. Al llegar a Málaga, es informado por algunos vecinos de la mala fama de la beata, por lo que recurre a la justicia para que "por el bien y pro de la dicha niña, se le provea un tutor y administrador de su persona y bienes" (50).

Evidentemente, las consecuencias que acarreaba la mala conducta a las mujeres no eran las mismas si se trataba de una vecina, de una moradora o "de asiento", o de una forastera o "estante". De todos modos, castigos tan drásticos que conllevasen la pérdida de la vivienda para aquellas personas cuya conducta no se ajustaba a la ley acabarían pronto. Estos ejemplos, que se producen en el año 1493 cuando se procede a una revisión del repartimiento inicial de casas a

(45) H. DILLARD: La mujer en la Reconquista, pp. 233-234.

(46) Véase J.Mª MIURA ANDRADE: "Algunas notas sobre las beatas andaluzas", en A. Muñoz (ed.): Las mujeres en el cristianismo medieval, Madrid, 1990, pp. 289-300; asimismo, "Formas de vida religiosa femenina en la Andalucía medieval. Emparedadas y beatas", en A. Muñoz y Mํㅡㄹ del Mar Graña (eds.): Religiosidad femenina: expectativas y realidades, Madrid, 1991, pp. 139-164.

(47) "Irónicamente, y en significación contraria (a la recta de carácter clerical) llama el vulgo a la mujer que, fingiéndose beata, vive mal y se emplea en tratos y exercicios indecentes y perversos. En cuanto a la "puta devota", puede aludir tanto a la prostituta que comercia fundamentalmente con la gente de iglesia, como a aquella otra que finge devoción para tener más fácil acceso a determinadas clases de la sociedad y protegerse so capa de santidad"; J.L. ALONSO HERNANDEZ: Léxico del marginalismo del Siglo de Oro, Salamanca, 1977, pp. 105 y 290.

(48) Fco. BEJARANO ROBLES: op. cit., p. 78: 9/II/1493.

(49) A.M.M., L.A.C., I, fol. 129: 11/X/1491.

(50) A.H.P.M., leg. 36, 5/V/151l. 
los primeros colonizadores, eran los últimos coletazos de un modelo de repoblación que pretendía, sin conseguirlo, prescindir de la gente de mal vivir para salvaguardar la convivencia cotidiana de un vecindario supuestamente honrado. Pero, ni durante el período en que los primeros repobladores esperaban los cinco años exigidos para acceder a la plena propiedad de sus casas, ni una vez cumplido el plazo, el amancebamiento y la prostitución pudieron erradicarse de una cildad portuaria como Málaga, visitada regularmente por marinos, mercaderes y hombres de negocio (51). Una vez asegurada la propiedad, el vecino que era acusado de vivir amancebado sufría una pena pecuniaria, como se pone de manifiesto en las relaciones de cuentas de los Libros de Penas de Cámara.

Vecinos y moradores vivieron, pues, amancebados; en ocasiones, con mujeres casadas o viudas, pero más frecuentemente con mujeres solteras, que encontraron en el concubinato una forma de subsistir en una sociedad donde la estima de la mujer se valoraba por sú relación con el hombre.

La presencia de mujeres sin marido, viudas o solteras, se constata en Málaga desde su incorporación a la Corona castellana, trabajando en oficios vinculados al sector alimenticio (52). Asimismo, fue temprana la presencia de mujeres que se ganaban la vida explotando una taberna, como se pone de manifiesto en diciembre de 1491, cuando el Concejo convoca a todos los mesoneros y taberneros "o mesoneras y taberneras que no tienen maridos", para informarles sobre cuestiones que atañen a la buena gobernación de la ciudad (53). Y si en los años noventa del siglo XV el número de mujeres taberneras apenas resulta significativo (54), a medida que transcurren los años abundan los testimonios de mujeres que se ganan la vida explotando una taberna, para lo cual debían de disponer de la correspondiente licencia municipal, que las autorizaba a vender vino, a guisar y a dar de: comer en sus casas y tabernas (55). Si se tiene en cuenta, además, que estaba terminantemente prohibido que en las tabernas se diese de comer a los vecinos casados, salvo a los bergantes y extranjeros (56), era lógico que una mujer casada, o cualquier mujer que quisiera contar con la estima de los demás, jamás se dedicara a regentar o trabajar en una taberna. En consecuencia, esta discriminación favorecía desde el punto de vista laboral a aquellas mujeres cuya reputación poco o nada importaba a los demás, pero, a cambio, su vida cotidiana transcurría en ambientes ien los que la presencia de marginados y gente de mal

(51) M T. LOPEZ BELTRAN: El puerto de Málaga en la transición a los tiempos modernos, Málaga, 1986, en particular el cap. IV.

(52) M T. LOPEZ BELTRAN: El trabajo extradoméstico en Málaga..

(53) A.M.M., L.A.C., I, fol, 143: 23 de diciembre de 1491.

(54) A principios de 1492, en la relación aprobada por el Concejo, de los doce taberneros que podían dar de comer y beber en la ciudad, tan sólo aparece una mujer, "La Trujilla", que tenía la taberna en la Ribera. Y en la relación aprobada de los veinte taberneros de pichel sólo aparece una mujer, Mari Rodríguez, con la taberna cerca de Santa María: A.M.M. L.A.C., I: 2 de enero de 1492.

(55) Para los años treinta del siglo XVI, son abundantes las noticias conservadas en A.M.M., Escti-

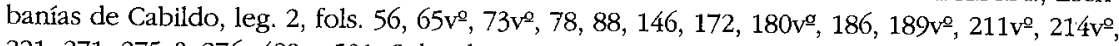
$221,271,275 \mathrm{v}^{\mathrm{o}}, 276,489$ y 501 . Sobre la normativa municipal, confróntese P. ARROYAL y $\mathrm{M}^{\mathrm{a}}$ T. MAR'TIN PALMA: Ordenanzas del Concejo de Málaga, Málaga, 1989, pp. 181-185.

(56) A.M.M., L.A.C., I, fols. $141 \mathrm{v}^{0}$ y $237 \mathrm{v}^{\circ}$. 
vivir era lo habitual. Ello justifica que los escasos contratos de trabajo referidos a tabernas y mesones de que dispongo, se concierten con mujeres viudas y solteras, vecinas o forasteras (57).

También el servicio doméstico se nutría de mujeres solteras. Pero, a diferencia del servicio doméstico adolescente, la parte contratante siempre es un hombre, cuyo estado civil no se declara, y las mujeres contratadas son mayoritariamente solteras y forasteras o "estantes" (58). La excepción la constituye María López, que entra a servir con el boticario Bartolomé Valles durante un año y por ocho ducados anuales, pagados trimestralmente. $Y$ es significativo que esta mujer, además de residente, sea negra (59).

Es muy posible que la convivencia de un hombre solitario con una sirvienta que ya ha alcanzado o sobrepasado la edad casadera fuese considerado potencialmente como un amancebamiento, o al menos se prestaba a la difamación. Sirva como ejemplo lo ocurrido a Diego de Badajoz, procurador del común, a quien el corregidor Juan Gaitán le prohíbe hacer uso del oficio hasta que no saliera del pecado en que estaba, pues "es público concupinario y está amancebado y en pecado públicamente". El procurador, que acaba acatando la decisión del corregidor, se defendió señalando que "si él está o ha estado como el dicho señor corregidor dice, no ha sido por deservir a la justicia ni mucho menos hacer a nadie agravio o perjuicio, porque hasta aquí es notorio a todos los que en la ciudad viven que él es hombre limpio y de buena fama, y que si ha tenido mujer en su casa ha sido porque había alguna causa para ello, porque él no se podía casar, y de esta causa se ha hecho hasta ahora" (60).

Ejemplos como el de este procurador del común, que vivía amancebado porque no se podía casar, fueron usuales en Málaga desde los inicios de la repoblación. En julio de 1489 , el Concejo insta a los jurados de las distintas colaciones a informarse "cómo viven los vecinos della y si hay vagamundos o abarraganado o onbres de mal trato e vivir" (61). No hay que olvidar que en todo lugar que se repuebla, y no sólo en Málaga, participaban hombres casados, viudos y solteros que se comprometían a traer a sus mujeres o a casarse en un plazo determinado (62). Pero hubo repobladores viudos y solteros que no se casaron, y repobladores casados que no pudieron o no quisieron traer consigo a sus mujeres; incluso, más de uno que vino con su mujer, se vio privado de su compañía porque fue desterrada de la ciudad. A todo ello hay que añadir la presencia de hombres foráneos, que como moradores pasan largas temporadas en la ciudad gestionando sus asuntos o como factores de compañías mercantiles nacionales o extranjeras.

Hombres todos ellos, pues, que encontraron en el amancebamiento la mejor manera de atender su casa, pese a que en la época los sirvientes eran usuales. Y la pesquisa de 1489 no debió servir de mucho, pues en noviembre de $1491 \mathrm{el}$

(57) A.H.P.M., leg. 63, 4/XII/1527; leg. 25 bis, (?)/III/1528.

(58) A.H.P.M., leg. 102, 16/V/1522; leg. 81, 27/LX/1524; leg. 103, 3/IV/1525; leg. 159, 7/IV/1530.

(59) A.H.P.M., leg. 64, 16/III/1528.

(60) A.C.M., leg. 63, pieza 75: 23 de abril de 1499.

(61) A.M.M., L.A.C., I: 24 de julio de 1489.

(62) H. DILLARD: La mujer en la Reconquista, passim. 
Concejo vuelve a instar a los jurados para que abrieran una información sobre las personas "malvivientes qué viven desonestamente, así los amancebados como.los revoltosos o otras cualesquier personas que viven mal (...) y los malos sean castigados" (63). Pero todo fue inútil. En septiembre de 1493, el corregidor insiste sobre el asunto porque "ha venido a su noticia que en la ciudad hay algunas personas que no viven tan bien como deben y algunas mugeres que no son casadas y viven amancebadas" (64).

Hubo hombres, pues, que vivian con concubinas y, aunque no estaban excluidas las mujeres casadas y viudas, la relación debió ser más frecuente con mujeres solteras y solitarias, cuya convivencia con un hombre sin estar casadas no perjudicaba el honor de terceros. Así, por ejemplo, Ana de Arano vive con el mercader catalán Gaspar Morell (65) en calidad de ama y, fruto de esa unión, tienen una hija llamada Isabel Morell que, pocos años después de fallecer su padre, es prohijada por su tía natural Olalla Solera, residente en Barcelona (66). La situación en que quedó Ana de Arano al fallecer el mercader a finales de 1507 no debió ser precaria, pues recibió 17.750 maravedís por resolución testamentaria; sin embargo, al poco tiempo de quedar sola se amanceba con Pedro Cherino, fiel del Concejo malagueño (67). Manceba también del regidor Fernando de Málaga fue Isabel Fernández de Villafranca (68); y, asimismo, Catalina de Cabeza era manceba del escribano público Alonso Martínez Tarégano, con el que posiblemente tuvo un hijo y que la compensó regalándole una esclava negra de diez años "por los muchos y buenos servicios que le ha hecho durante el tiempo que con ella ha tenido amistad y conocimiento, y porque le ha criado con sus pechos a Francisco, su hijo, lo cual hasta ahora no se lo había gratificado ni pagado, y por el mucho amor y buena voluntad que le tiene" (69).

Pero no siempre conseguía una mujer soltera establecer una relación más o menos duradera con un hombre, y menos aún de la posición de los antedichos, por lo que la prostitución transitoria o definitiva se convertía en su única opción.

\section{LAS PROSTITUTAS}

Todo lo expuesto hasta el momento permite constatar que la marginación se nutría de mujeres pobres a las que por diversas causas les habían fallado la familia y el matrimonio, y a las que otras alternativas (bigamia y amancebamiento) les dificultaban enormemente la integración. Y en la sociedad de la época, las muje-

(63) A.M.M., L.A.C., I: 1 de noviembre de 1491.

(64) A.M.M., L.A.C., I: 27 de septiembre de 1493.

(65). Sobre los mercaderes catalanes y sobre la familia Morell, véase $\mathrm{M}^{\mathrm{n}} \mathrm{T}$. LOPEZ BELTRAN: "La "nación" catalana en la repoblación y conformación de la sociedad malagueña (1487-1538)", Baética, 11(Univ. de Málaga; 1988); pp. 367-376).

(66) A.H.P.M., leg. 720, 1/TI/1518.

(67) A.H.P.M., leg. 10, 18/II/1508 y $14 / \mathrm{XIL} / 1508$.

(68) A.H.P.M., leg. 10, II, 14/XII/1508.

(69) A.H.P.M., leg. 35, 25/IX/1516. 
res marginadas que más centraron la atención de los legisladores fueron las prostitutas, cuya existencia fue objeto de una constante reglamentación (70).

Todos los tratadistas sobre el tema coinciden en señalar que la pobreza y la pérdida del honor fueron determinantes en aquellas situaciones en que la mujer se veía abocada a la prostitución, ya fuese reglamentada o no. Pero hay que entender el honor en el sentido más amplio del término (71) y teniendo en cuenta que en la sociedad de la época el honor de la mujer se valoraba socialmente de acuerdo con su estado civil (72). En consecuencia, las mujeres más proclives a la prostitución fueron aquellas a las que habían fallado los recursos tradicionales y a las que la más mínima eventualidad sumía en una situación de carencia. Es decir, las mujeres solitarias, carentes de protección por hombres de la familia y cuyo honor, por tanto, era vulnerable a las agresiones.

Para Málaga no disponemos de datos sobre la procedencia y estado civil de las prostitutas, pues en las relaciones que se conservan en los archivos locales todas constan como "estantes" y ocultan su identidad, distinguiéndose en el gremio por algún rasgo físico o por determinada particularidad ("la delgadilla", "la chica", "la zamorana"...). Es cierto que las dificultades que entraña disponer de

(70) Entre los estudios dedicados al tema, merecen destacarse: BULLOUG, V.L y BULLOUG, B.: The bistory of prostitution, New York, 1964; BULLOUG, V.: "The Prostitute in the Middle Age", Studies in Medieval Culture, 10 (1977), pp. 9-17; GEREMEK, B.: "Criminalité, vagabondage, paupérisme: la marginalité à l'aube des temps modernes", Revue d'Histoire Moderne et Contemporaine, XXI (1974), pp. 337-375; Les Marginaux Parisiens au XVe Siécles, París, 1976; GRAULLERA SANZ, V.: "Un grupo social marginado: las mujeres públicas (el burdel de Valencia en los siglos XVI y XVII)", Coloquio de Pau sobre Historia de Valencia (Valencia, 1978), pp. 75-98; LOPEZ BELTRAN, M⿳⺈ ${ }^{\mathrm{a}}$ T.: La prostitución en el reino de Granada en época de los Reyes Católicos: el caso de Málaga (1487-1516), Málaga, 1985; "Evolución de la prostitución en el Reino de Granada a través de las ordenanzas de la mancebía de Ronda", Realidad bistórica e invención literaria en torno a la mujer, Málaga, 1987, pp. 11-23; PADILLA GONZALEZ, J. y ESCOBAR CAMACHO, J.M.: "La mancebía de Córdoba en la Baja Edad Media", Actas del III Coloquio de Historia Medieval Andaluza. La sociedad medieval andaluza: grupos no privilegiádos (Jaén, 1984), pp. 279-289; PAVAN, E.: "Police des moeurs, societé et politique a Venice á la fin du Moyen Age", Revue Historique, 536 (1981), pp. 241-288. PERIS, M ${ }^{a}$ C.:"La prostitución valenciana en la segunda mitad del siglo XIV", Revista d'Historia Medieval, 1 (Valencia, 1990), pp. 179-213; PUIG, A. y TUSSET, M.: "La prostitución en Mallorca (siglos XIV, XV y XVI)", La condición de la mujer en la Edad Media, Madrid, 1986, pp. 273-288; ROPER, L.: The boly bousehold, Oxford, 1989; RUGGIERO, G.: The boundaries of eros. Sex, crime and sexuality in Renaissance Venice, Oxford, 1985; ROSSIAUD, J.: La prostitución en el Medievo, Barcelona, 1986; TREXLER, R.C.: "La prostitution florentine au XVe siécle: patronages et clientéles", Annales ESC, 6 (1981), pp. 983-1015; VAZQUEZ GARCIA y MORENO MENGIBAR: "Documentos sobre el prostíbulo de Sevilla. Siglos XVI-XIX", Revista de Filosofía ER núms. 7/8 (Sevilla, 1989), pp. 325-379.

(71) Es decir, honra personal, que depende del destino que cada mujer de a su cuerpo; buena fama, siempre que la mujer viva con recato dentro de los límites a ella marcados; y honra familiar, en tanto que la mujer la recibe del hombre, ya sea padre o marido: $M^{\mathrm{a}} \mathrm{I}$. PEREZ DE TUDELA Y VELASCO: "La mujer castellano-leonesa del pleno medievo. Perfiles literarios, estatuto jurídico y situación económica", Las mujeres y su ámbito jurídico, Madrid, 1983, pp. 68-70.

(72) H. DILLARD:op. cit., passim. C. SEGURA GRAIÑO: "La mujer como grupo no privilegiado en la sociedad andaluza bnajomedieval. Situación jurídica", Actas del III Coloquio de Historia Medieval Andaluza, pp. 227-236. 
testimonios directos sobre las prostitutas se pueden superar en buena medida acudiendo a los testamentos, si bien, para el caso de Málaga y para el período por mí estudiado, el vaciado de testamentos no ha sido todo lo fructífero que deseaba (73).

En la época que nos ocupa, la amplitud y generalización de la prostitución femenina, tanto en el ámbito rural como en el urbano, fue un problema que los poderes públicos de la época intentaron controlar, fijando los límites admisibles en que debía desarrollarse. En consecuencia, las prostitutas no son consideradas delincuentes por la función que ejercen (74), sino trabajadora. $Y$ en este sentido, buena parte de los estudios consagrados al tema se han centrado casi exclusivamente en el análisis de la prostitución desde la perspectiva de un oficio perfectamente reglamentado, aunque marginal, el más marginado de todos los oficios que una mujer pueda desempeñar (75).

En el ámbito granadino (76), al igual que en otras zonas del Occidente europeo, una de las grandes preocupaciones de la Corona era la de salvaguardar la buena reputación de las mujeres honestas, promulgando leyes que confinaban a las prostitutas a zonas concretas de la ciudad, al tiempo que se las obligaba a vivir y a trabajar únicamente en las mancebías o lugares autorizados (en ocasiones, cuando se trataba de zonas de escasa entidad urbana, los mesoneros podían ser autorizados por las autoridades concejiles a disponer de prostitutas). Asimismo, se promulgan leyes sobre su vestimenta, tanto en el sentido de obligarlas a llevar un distintivo de su profesión (la toca azafranada o la mantilla corta y encarnada), como en el sentido de prohibirles el lujo y la ostentación (joyas, pieles, sedas...). También la Corona legisla sobre otros muchos aspectos relacionados con el mundo de la prostitución, promulgando leyes tendentes a evitar alteraciones de orden público en los lugares frecuentados por las prostitutas (tabernas y mesones), o persiguiendo al proxeneta o rufián, al que se considera no sólo causante de este desorden público, sino también de la existencia misma de la prostitución...

(73) En efecto, pues para un espacio temporal que abarca desde el año 1496, año del que parten los protocolos notariales más antiguos conservados, hasta el año 1538, tan sólo he encontrado dos testamentos referidos a prostitutas. El, primero de ellos, el de Catalina de Espíndola, "mujer de la ramería", que se encuentra enferma y decide testar en beneficio del hospital de San Sebastián, declarando sus escasos bienes y las deudas contraídas, pero sin indicar referencias sobre su entorno familiar. El otro testamento es el de Inés de Torres, "mujer de la mancebía", que entra de hermana en el hospital de la Santa Caridad de Málaga, dejando como herederos de sus pocos bienes a Rodrigo de Bustos y a Constancia Díaz, sus padres, que viven en Córdoba, en la colación de la Magdalena: A.H.P.M., leg. 165, 10/V/1533 y leg. 51, 4/VIII/1537, respectivamente.

(74) Ello justifica que en las relaciones contenidas en los libros de Penas de Cámara que se suelen conservar en los archivos municipales, no aparezcan prostitutas, del mismo modo que tampoco aparecen en las relaciones de procesados por la Inquisición granadina.

(75) Véase al respecto, $M^{a} T$. LOPEZ BELTRAN: "La experiencia silenciada. Las mujeres en la Andalucía medieval cristiana", Las Mujeres en la Historia de Andalucía. Actas del II Congreso de Historia de Andalucía, (Córdoba, 1994), pp. 23-34.

(76) Cf. $M^{\mathrm{a}} \mathrm{T}$. LOPEZ BELTRAN: La prostitución en el reino de Granada en época de los Reyes Católicos: el caso de Málaga (1487-1516), Málaga, 1985. 
Sin embargo, la prostitución reglamentada en el reino de Granada presenta una singularidad en relación a la de otras partes del Occidente europeo: por merced regia y sin haber finalizado la incorporación definitiva del reino de Granada a la Corona castellana, las mancebías de todo el reino quedan monopolizadas por la familia murciana de los Fajardo, lo que significaba que las arcas municipales no se iban a beneficiar de la prostitución reglamentada.

Empero, en lo que a Málaga se refiere, los garantes del orden y de la moral pública van a utilizar todos los medios a su alcance para participar en las rentas de la prostitución, y en particular, van a ejercer una amplia e interesada permisividad con un grupo de mujeres que optan por la prostitución para solventar sus problemas, pero que se niegan a trabajar en la mancebía de la ciudad, denominadas en la documentación de la época "mujeres enamoradas". Al mismo tiempo, y también de manera interesada, las autoridades concejiles se convierten en los defensores a ultranza de las mujeres de la mancebía, que viven y se sienten oprimidas por las condiciones draconianas del prostíbulo.

Pero no interesa aquí reiterar cuestiones ampliamente tratadas en otro lugar (77), sino llamar la atención sobre un fenómeno social que, con frecuencia, se subestima al abordar el análisis de la prostitución. Me refiero a la existencia, paralela a la prostitución reglamentada, de una prostitución más o menos clandestina, la ejercida por las "mujeres enamoradas", que podia significar un paso intermedio, pero no necesariamente, hacia la prostitución reglamentada, y que está intimamente vinculada a los mecanismos de supervivencia, individuales y familiares.

¿Quiénes eran las mujeres enamoradas?. En opinión de las autoridades concejiles, las mujeres enamoradas (78) no eran iguales que las putas "que ganavan por las tavernas e bodegones e otras partes" (79). Es decir, eran mujeres establecidas en la ciudad, bien como vecinas o como moradoras, diferenciándose de las mujeres de la mancebía, que eran "estantes" y desconocidas, cuya vida transcurría de ciudad en ciudad, y de prostíbulo en prostíbulo, frecuentando malas compañías y, en más de un caso, huidas de la justicia de otros lugares por deudoras.

En consecuencia, las "mujeres enamoradas", pese a declicarse a la prostitución, no carecían de una cierta estima en el vecindario, sobre todo si se tiene en cuenta que su clientela se nutría de hombres casados, a los que les estaba prohibido entrar en las tabernas y mesones de la ciudad (80). Y la norma que era válida para el ciudadano hontado, también lo era para el forastero honrado que huía de ambientes nada recomendables.

(77) Ma T. LOPEZ BELTRAN: op. cit, passim.

(78) Ibídem, pp. 78-79.

(79) El término "enamorada" hace referencia a la mujer cuya ocupación es la prostitución pero que trabaja por libre: J.L. ALONSO HERNANDEZ: El lenguaje de los maleantes españoles de los siglos XVI y XVII: La Germanía. (Introducción al léxico del marginalismo). Salamanca, 1979, pp. 26-27.

(80) A.M.M., L.A.C., I: 5 de diciembre de 1491, fecha en que el Concejo establece que "en las tabernas no se den de comer a hombre casado alguno, salvo a los vergantes y extrangeros". Posteriormente, en 25 de agosto de 1493, se promulga una ordenanza sobre los casados, que establecía "que el vecino casado que se tomare en cualquier taberna comiendo o bebiendo, si es la primera vez, pagará una mullta de 600 maravedís; la segunda, la pena doblada y treinta días de cárcel": A.M.M., L.A.C., I. 
Es posible que estas mujeres, que no estaban aisladas del resto del vecindario, viviesen en zonas o calles determinadas y localizadas por la costumbre existente en la época de colocar un ramo verde a la puerta de sus casas para indicar que eran prostitutas (81), de manera que no se establecieran confusiones y malos entendidos con las mujeres honradas. Y estas zonas o calles determinadas recibían el nombre genérico de ramería, sin aludir en principio a un recinto determinado.

Nada indica la documentación estudiada sobre el estado civil de las "mujeres enamoradas", pero si tenemos en cuenta las ordenanzas de la mancebía de Ronda (82), muchas mujeres casadas de la ciudad debieron recurrir a la prostitución para complementar su exigua remuneración laboral cotidiana o para vivir exclusivamente de ella. Pero resulta difícil imaginar a las mujeres casadas de la ciudad ejerciendo la prostitución con la aprobación de sus maridos, pues dada la ideología del honor imperante, esas situaciones lesionaban el honor masculino. Posiblemente se tratase de mujeres casadas que se ven injustamente sin la compañía de sus maridos, lo que legitimaba a los ojos del vecindario un trabajo totalmente rechazable en otras circunstancias.

A las "mujeres enamoradas", dueñas de su sexualidad y de su trabajo, se oponían las mujeres de la mancebía, que carecían de libertad laboral y de cuyo trabajo se beneficiaban rufianes y arrendatarios de la mancebía. En efecto, eventualidades ajenas a su voluntad, de las que se aprovechan en muchos casos los organizadores de la oferta y de la demanda del sexo, las llevan, irremediablemente, al prostíbulo, del que difícilmente pueden salir al endeudarse por las condiciones draconianas que imperaban en él y que respondian a un triple concepto: alquiler de las "boticas", comidas y préstamos en metálico, como ponen de manifiesto las numerosas cartas de obligación registradas en los protocolos, amén de las deudas contraídas con traperos y prestamistas locales, relacionadas en casi todos los casos con su vestimenta (83).

De todos modos, las ventajas de que disfrutaban las "mujeres enamoradas", si no desaparecieron, se vieron enormemente recortadas al disponer la ciudad de una ramería que, en definitiva, significó una unificación laboral para todas aquellas mujeres que se dedicaban a la prostitución, denominándoselas indistintamente "rameras", "mujeres del mundo", "mujeres de partido", "mujeres públicas" y "mujeres de la mancebía" (84).

(81) J.L. ALONSO HERNANDEZ: Léxico del marginalismo del Siglo de Oro, Salamanca, 1977, p. 653.

(82) M $M^{a}$ T. LOPEZ BELTRAN: "Evolución de la prostitución en el Reino de Granada através de las ordenanzas de la mancebía de Ronda", Realidad histórica e invención literaria en torno a la mujer, Málaga, 1987, pp. 11-23. En efecto, las ordenanzas prohíben que "las mugeres casadas que tengan sus padres en esta ciudad" vivan de la prostitución, sin mencionar para nada a sus maridos.

(83) Cf. M ${ }^{a} T$ T. LOPEZ BELTRAN: La prostitución en el reino de Granada..., passinn. Asimismo, en colaboración con A. Galán Sánchez, "El "status" teórico de las prostitutas del reino de Granada en la primera mitad del siglo XVI. (Las ordenanzas de 1536)", Las mujeres en las ciudades medievales, Madrid, 1984, pp. 161-169.

(84) $M^{a} \mathrm{~T}$. LOPEZ BELTRAN: La prostitución en el reino de Granada..., en particular Cap. VI. 